\title{
Excitatory Amino Acids Contribute to the Patho- genesis of Perinatal Hypoxic-Ischemic Brain Injury
}

\author{
John D.E. Barks ${ }^{1}$ and Faye S. Silverstein ${ }^{2}$ \\ ${ }^{1}$ Department of Pediatrics, University of Michigan, Ann Arbor, \\ MI 48109-0570, U.S.A. \\ 2 Department of Neurology, University of Michigan, Ann Arbor, \\ MI 48109-0570, U.S.A.
}

\begin{abstract}
A large body of experimental evidence indicates that over-activation of excitatory amino acid (EAA) receptors may mediate irreversible neuronal injury in a variety of pathologic settings including cerebral ischemia, and that the developing brain may be particularly susceptible to the adverse effects of EAA receptor overactivation. In this article, we review current information about EAA receptor pharmacology and EAA neurotoxicity in the immature brain, and summarize recent experimental data indicating that EAA contribute to the pathogenesis of perinatal hypoxic-ischemic brain injury.
\end{abstract}

\section{Introduction}

In the last decade, several seminal observations have provided support for the hypothesis that endogenous excitatory amino acid (EAA) neurotransmitters (e.g., glutamic acid) play a major role in the pathgenesis of hypoxic-ischemic neuronal injury. In vitro, in cultured hippocampal neurons, Rothman first demonstrated that anoxic neuronal injury was dependent on synaptic activity; a substantial body of subsequent work confirmed that EAA mediated anoxic neuronal injury in vitro (1). Concurrently, in experimental animal models of ischemic brain injury, a variety of experimental strategies yielded complementary evidence that EAA contributed to the pathogenesis of irreversible ischemic neuronal injury. Important findings included: the recognition that regions with high densities of EAA receptors were particularly susceptible to ischemic injury (2),

Corresponding author:

Dr. J.D.E. Barks, Room 6028, Kresge II Building, Box 0570 ,

University of Michigan, Ann Arbor, Ml 48109-0570, U.S.A.

Tel. +1 (313) 764 2116; Fax +1 (313) 7644279 observations that intra-cerebral injection of the competitive EAA antagonist arninophosphonoheptanoic acid (AP7) attenuated acute ischemic neuronal damage (3) and that preceding deafferentation reduced ischemic damage to highly vulnerable hipppocampal neurons (4), and results of in vivo microdialysis studies that demonstrated directly substantial increases in hippocampal extracellular glutamate concentrations during cerebral ischemia (5). In the immature nervous system, Hagberg et al. demonstrated that in fetal lambs, cerebral ischemia resulted in marked rises in cortical and striatal glutamate content (6) and McDonald et al. showed that treatment with the noncompetitive. EAA antagonist MK-801 [(+)-5methyl-10,11-dihydro-5H-dibenzo-(a,d)-cyclohepten5,10 -imine maleate] was neuroprotective in a model of perinatal focal cerebral ischemia (7).

Current important experimental questions include elucidation of the distinct roles of EAA in the pathogenesis of neuronal injury after focal and global ischemia, development of effective neuroprotective interventions based on EAA pharmacology $(8,9)$, and understanding the potential adverse effects of drugs acting at EAA receptors. In this review, we will present results of recent studies that provide important new insights about the potential contributions of EAA to perinatal hypoxic-ischemic brain injury.

\section{Excitatory Amino Acid (EAA) Pharmacology}

An understanding of EAA neuropharmacology is an essential prerequisite for analysis of the role of EAA in the pathogenesis of brain injury and for development of therapeutic strategies based on EAA receptor blockade. In theory, it would be possible to modulate EAA synaptic function by altering synthesis, release, re-uptake of EAA, or receptor activation. Few pharmacologic agents with specific pre-synaptic actions

\begin{tabular}{|ll|}
\hline Glossary for Abbreviations \\
\hline EAA & Excitatory amino acids \\
PND & Post-natal day \\
ECF & Extracellular fluid \\
HPLC & High performance liquid chromatagraphy \\
\hline
\end{tabular}


have been developed, and EAA pharmacology is currently focused primarily on analysis of post-synaptic receptors.

Several classsification schemes for EAA receptors have been devised, based on their selective responses to the agonists N-methyl-D-aspartate (NMDA), quisqualic acid and kainate, and on their signal transduction mechanisms (ionotropic or metabotropic) (10-12).

NMDA receptor-channel complex. The NMDA-receptor channel complex includes the EAA recognition site, a voltage-dependent cation channel permeable to both sodium and calcium, which, at rest, is blocked by magnesium, and a strychnine-insensitive glycine receptor that is activated by physiologic concentrations of glycine. Several distinct groups of NMDA antagonists, with different loci of action, have been identified (13). The NMDA receptor-channel complex can be blocked competitively at its agonist binding site, by compounds such as aminophosphonoheptanoic acid (see Table). Non-competitive antagonists such as phencyclidine (PCP) and MK-801 [ (t)-5-methyl-10, 11-dihydro-5H-dibenzo (a,d) cyclohepten-5-10-imine maleate] bind at sites within the ion channel, and glycine antagonists (e.g., 7chlorokynurenate) can also functionally block NMDA receptor activation (see Table). Distinct binding sites for polyamines have also been identified, and polyamines appear to be have complex regulatory influences on NMDA-receptor function (14).

Many recent studies have evaluated the neuroprotective efficacy of competitive and non-competitive NMDA antagonists in experimental animal models of ischemic brain injury. Numerous reports have demonstrated efficacy in models of focal cerebral ischemia (15-17), however, other studies attributed beneficial effects to non-EAA-mediated effects (18). Furthermore, in models of global cerebral ischemia, generally, NMDA antagonists have not proven to be effective neuroprotective agents (19).

Another important observation relevant to the potential therapeutic actions of NMDA antagonists is their potential deleterious effects (20); Olney and colleagues first reported that MK-801 induced acute vacuolar degeneration in selected cell populations and subsequently showed that these degenerative changes could be prevented by concurrent administration of anti-cholinergic drugs or diazepam (21).

Non-NMDA receptors. There are two groups of quisqualate-sensitive receptors, those linked with a cation channel and selectively. responsive to the agonist alpha-amino-3-hydroxy-5-methyl-4-isoxazole propionate (AMPA), and the metabotropic quisqualate receptor (linked with phospholipase C). A distinct group of EAA receptors respond selectively to kainic acid. The ionotropic receptors are linked with cation channels permeable to sodium. Effective AMPA receptor antagonists have also recently been developed. The systemically administered AMPA receptor antagonist 2,3-dihydroxy-6-nitro-7-sulfamoyl-benzo (f) quinoxaline (NBQX) is neuroprotective in models of global cerebral ischemia in adult gerbils and rats (22-24).

Recent advances in molecular analysis of EAA receptor encoding genes suggest that there may be considerably greater diversity in EAA receptor expression than is currently discernible pharmacologically. Multiple genes encoding EAA receptors or constituent subunits have been cloned, and ontogenetic changes in the regional distributions of the mRNAs for specific EAA receptor subunits have been identified (25).

\section{EAA-Mediated Neurotoxicity}

A large body of experimental data indicates that over-activation of EAA receptors by endogenous or exogenous agonists can cause neuronal damage (the concept of "excitotoxicity") (26). Increased activation of EAA receptors could reflect elevated synaptic concentrations of EAA (because of increased release or failure of neuronal or glial re-uptake) or increased receptor sensitivity to the agonist.

Molecular mechanisms of neurotoxicity. The molecular mechanisms that mediate EAA-induced injury have, for the most part, been elucidated in vitro. Current evidence indicates that overwhelming increases in free intracellular calcium (attributable to increased entry through NMDA and voltage-gated channels and inability of mitochondria to compensate) represent the final common pathway of EAA-mediated injury (27). The blockade of NMDA-induced calcium entry by the neuroprotective non-competitive antagonist MK-801 has recently been documented in vivo (28).

Relevant to understanding EAA-mediated mechanisms in ischemic injury is the observation that the vulnerability of cultured neurons to glutamate neurotoxicity rises during glucose deprivation, anoxia or pharmacologic inhibition of oxidative phosphorylation (29), perhaps because of limited adaptive capacity of metabolically compromised mitochondria to rises in free intracellular calcium. In fact, the relationship between compromised energy state and susceptibility to EAA-mediated injury may be relevant to the pathogenesis of irreversible injury in a variety of pathologic conditions (for review, see Ref. 30).

Excessive EAA-receptor activation may have other potentially deleterious effects as well. In some cell populations, EAA's activate phospholipase A2, and stimulate release of arachidonic acid (31). Arachidonic acid has many potential deleterious effects on cell membranes; in addition, it may directly suppress neuronal and glial EAA re-uptake mechanisms and thereby contribute to synaptic EAA accumulation 
Table 1 Drugs acting at excitatory amino acids (EAA) synapses

\begin{tabular}{|c|c|c|}
\hline Receptor/Site & Agonists & Antagonists \\
\hline \multicolumn{3}{|l|}{ NMDA } \\
\hline EAA recognition & Glutamate, NMDA & AP-5, AP-7, CPP, CGS-19755 \\
\hline Ion channel & Unknown & $\begin{array}{l}\text { MK-801, PCP, TCP, dextro- } \\
\text { methorphan, ketamine }\end{array}$ \\
\hline Glycine site & Glycine, D-serine & $\begin{array}{l}\text { Kynurenate, 7-chlorokynurenate, } \\
\text { HA-966, CNOX, DNOX }\end{array}$ \\
\hline AMPA & $\begin{array}{l}\text { Glutamate, AMPA, quis- } \\
\text { qualate, kainate, ibotenate }\end{array}$ & NBOX, CNOX, DNOX \\
\hline Metabotropic & $\begin{array}{l}\text { Glutamate, quisqualate, } \\
\text { trans-ACPD, ibotenate }\end{array}$ & Aminophosphonoproprionic acid \\
\hline Kainate & $\begin{array}{l}\text { Glutamate, kainate, } \\
\text { domoate }\end{array}$ & CNOX, DNOX, kynurenate \\
\hline \multicolumn{2}{|l|}{ Abbreviations } & . \\
\hline AMPA & \multicolumn{2}{|l|}{ Alpha-amino-3-hydroxy-5-methyl-4-isoxazole propionate } \\
\hline APS & \multicolumn{2}{|l|}{$D(-)$-2-amino-5-phosphonovalerate } \\
\hline AP7 & \multicolumn{2}{|l|}{$D(-)$-2-amino-7-phosphonoheptanoate } \\
\hline CPP & \multicolumn{2}{|l|}{$3(-)$-2-carboxypiperazin-4-ylpropyl-1-phosphonate } \\
\hline CGS- 19755 & \multicolumn{2}{|l|}{ cis-4-phosphonomethyl-2-piperidine carboxylate } \\
\hline CNOX & \multicolumn{2}{|l|}{ 6-cyano-7-nitroquinoxaline-2,3-dione } \\
\hline DNOX & \multicolumn{2}{|l|}{ 6,7-dinitroquinoxaline-2,3-dione } \\
\hline HA-966 & \multicolumn{2}{|l|}{ 1-hydroxy-3-aminopyrrolid-2-one } \\
\hline MK-801 & \multicolumn{2}{|c|}{ (t)-5-methyl-10,11 l-dihydro-5H-dibenzo-[a,d]-cyclohepten-5,10-imine maleate } \\
\hline NBOX & \multicolumn{2}{|l|}{ 2,3-dihydroxy-6-nitro-7-sulfamoyt-benzo(f) quinoxaline } \\
\hline NMDA & \multicolumn{2}{|l|}{$\mathrm{N}$-methyl-D-aspartate } \\
\hline PCP & \multicolumn{2}{|l|}{ Phencyclidine } \\
\hline TCP & \multicolumn{2}{|l|}{ 1-[1-(2-thienyl)-cyclohexyl] piperindine } \\
\hline Trans-ACPD & \multicolumn{2}{|l|}{ Trans-1-aminocyclopentane-1,3-dicarboxylate } \\
\hline
\end{tabular}

(32). Recent data suggest that NMDA neurotoxicity may also be mediated by activation of ornithine decarboxylase, which results in increased polyamine synthesis. The polyamine synthesis inhibitor alphadifluoromethylornithine blocked NMDA-induced neurotoxicity in vitro (33) and in vivo (34). EAA may also stimulate formation of nitric oxide (NO) (35); both in vitro and in vivo data suggest that NO may be neurotoxic (36). Treatment with $\mathrm{NG}_{-}$Nitro-L-arginine, a compound that blocks NO synthesis, limited the severity of injury in an adult rodent model of focal ischemic brain injury (37).
EAA neurotoxicity in the developing brain. Immature neurons may be particularly sensitive to the deleterious effects of EAA receptor overactivation. The ontogeny of excitotoxicity has been studied by histopathologic assessment of brain injury after direct intra-cerebral injections of agonists at different developmental stages. In contrast with the resistance of the immature mammalian brain to kainic acid, NMDA neurotoxicity peaks in the early post-natal period. The neurotoxicity of NMDA in hippocampus, striatum and neocortex is maximal in the immature rat brain, peaking at postnatal day six to seven 


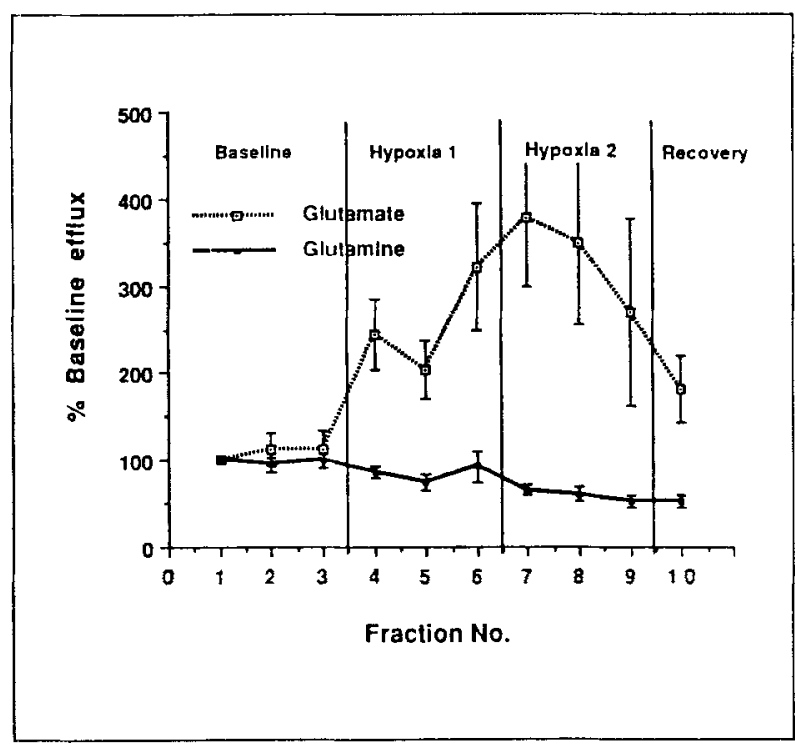

Figure 1 Hippocampal glutamate efflux during perinatal hypoxia-ischemia: Microdialysis probes were inserted into the right hippocampus of PND 7 rats that underwent right carotid ligation, followed by exposure to $8 \%$ oxygen for two hours ( $n=6$, see Ref. 56 for methods). Beginning two hours after probe insertion, ten sequential 20 minute dialysis samples were collected from each animal. Amino acid content of dialysates was quantitated by an HPLC assay. This graph compares sequential hippocampal glutamate and glutamine efflux values, expressed as \% baseline, in six animals that underwent right carotid artery ligation followed by two hours of $8 \%$ oxygen exposure. Baseline values were defined as the averages from the first three fractions collected in each animal.

Reproduced from Referece 56, with permission from The Intemational Society for Pediatric Research.

$(38,39)$. Stereotaxic injections of NMDA $(5-25 \mathrm{nmol})$ into posterior striatum produce dose-dependent injury with neuronal necrosis in striatum and overlying dorsal hippocampus and cortex. At this developmental stage, susceptibility to quisqualic acid neurotoxicity is also relatively high, as compared with adult brain (40); yet, NMDA is considerably more toxic (100 nmol quisqualate or $10 \mathrm{nmol}$ NMDA elicit injury of similar severity) (41). Intracerebral injection of glutamate typically results in no injury because of rapid neuronal and glial uptake; yet, injections of massive doses may also produce small brain lesions (42).

Enhanced sensitivity of the immature brain to EAAinduced toxicity could reflect increased receptor density, altered receptor sensitivity (due to age-related differences in the molecular constitution of EAA receptors), or differences in modulatory or compensatory mechanisms. Autoradiographic receptor binding assays indicate that in certain regions (e.g. hippocampus, globus pallidus), the immature brain has a higher density of both NMDA and non-NMDA type EAA receptors than adult brain; however, the ontogenetic peaks of receptor density and susceptibility to neurotoxicity do not coincide precisely (43-46). In electrophysiologic studies, hippocampal pyramidal neurons show maximal responsiveness to NMDA at PND 5 to 9 (47), and immature hippocampal neuron NMDA receptor/channels are less susceptible to blockade by $\mathrm{Mg}^{++}$and more sensitive to modulation by glycine $(48,49)$ or polyamines $(14)$. Alternatively, some populations of immature neurons may be less able to buffer EAA-induced increases in free intracellular calcium, due to immaturity of mechanisms such as the calcium-binding protein calbindin D28k (50).

\section{EAA and Perinatal Hypoxic-Ischemic Brain Injury}

Several complementary experimental approaches have been used to examine the role of EAA in the pathogenesis of perinatal hypoxic-ischemic brain injury. An experimental model of perinatal stroke, elicited by unilateral carotid ligation and subsequent timed exposure to moderate hypoxia in immature rats, has been used extensively in these studies (51). In seven day old rats, unilateral carotid ligation followed by exposure to an $8 \%$ oxygen/balance nitrogen atmosphere for 2 to 3.5 hours elicits ipsilateral forebrain injury. Neither ligation alone or hypoxia alone cause tissue injury; after ligation, superimposed hypoxia results in progressive ipsilateral ischemia (52). The threshold duration of $8 \% \mathrm{O}_{2}$ exposure that results in tissue injury is close to 1.5 hours. Overall, the severity of injury then increases with increasing duration of hypoxia. However, in this preparation, for unexplained reasons, there is considerable variability in the severity and histopathologic features of injury in lesioned animals. In this perinatal model, the propensity for selective CA1 pyramidal cell damage which characterizes ischemic brain injury in adult models, is not observed. The features of hippocampal histopathology are somewhat variable; of note, dentate gyrus neurons (considered relatively resistant to ischemic injury in adult brain) are often injured.

Alterations in endogenous EAA. In this perinatal stroke model, the first evidence that focal ischemic brain injury disrupted the functional integrity of EAA synapses was the observation that in target areas for irreversible ischemic injury (striatum and hippocampus) high-affinity glutamate uptake was acutely (and reversibly) suppressed during the evolution of injury. The importance of this finding was that it suggested a credible pathophysiologic mechanism that could account for acute accumulation of EAA in the synaptic cleft (53).

Subsequent studies using in vivo microdialysis provided more direct evidence that EAA accumulated in extracellular fluid (ECF) acutely with hypoxicischemic injury. In brain, ECF accumulation of neurotransmitters reflects regional synaptic concentra- 


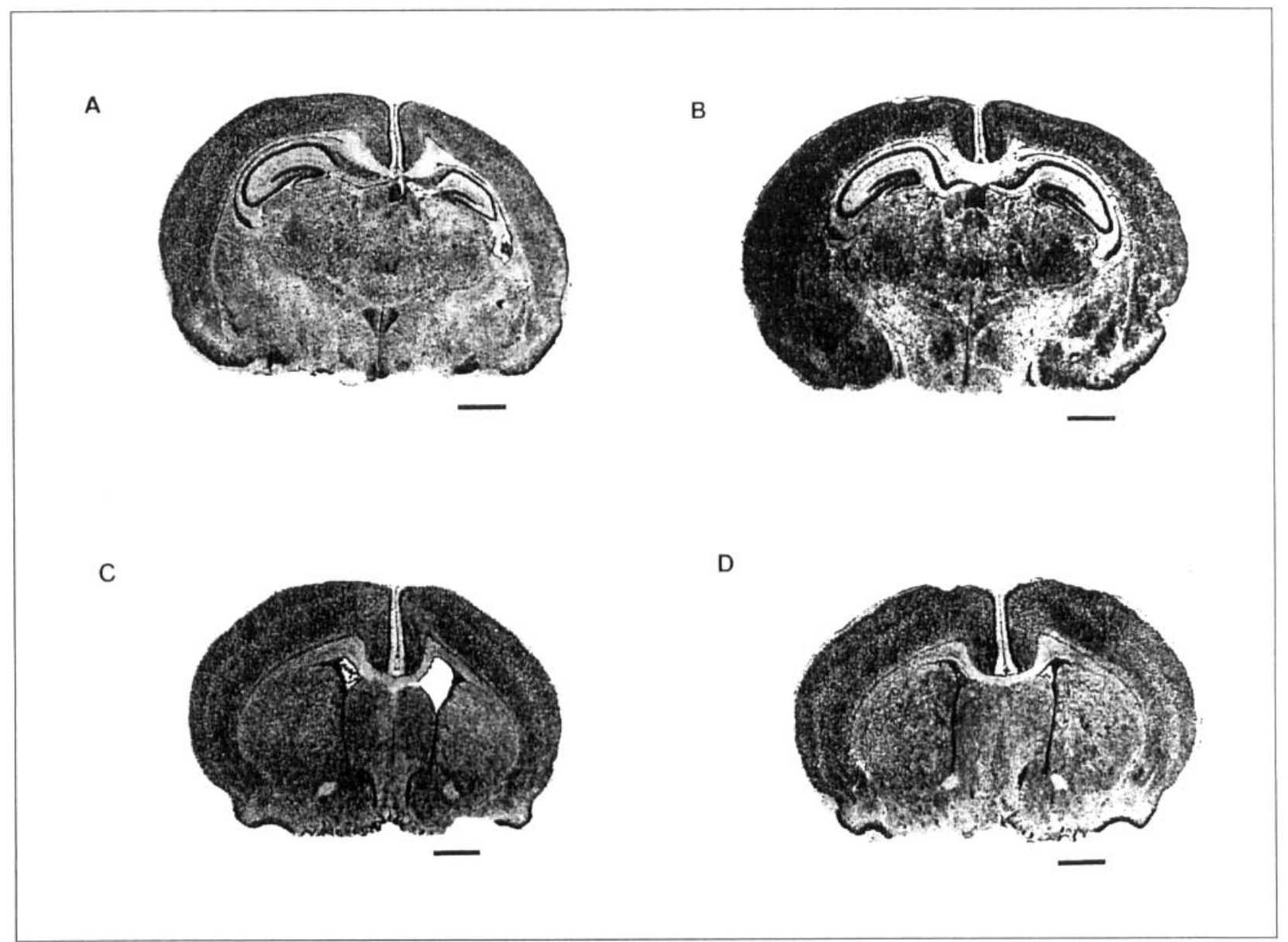

Figure 2 Glutamate antagonist neuroprotection: Both animals were subjected to right carotid ligation followed by three hours in $8 \%$ oxygen on PND 7. Brains were removed on PND 12, sectioned and stained with Cresyl violet. Sections in panels B and D are from an animal pretreated with MK-801 $1 \mathrm{mg} / \mathrm{kg}$; sections in panels $A$ and $C$ are from a vehicle-treated control. Coronal-sections in panels $A$ and $B$ are at the level of the dorsal hippocampus; sections in panels $C$ and $D$ are at the level of the striatum. Note the reduction in size of the right hippocampus and striatum in the control animal (panels $\mathrm{A}, \mathrm{C}$ ), which is not discernible in the MK-801 pretreated animal (panels B,D). Scale bar $-1.6 \mathrm{~mm}$.

Reproduced from Reference 63, with permission from The American Heart Association.

tions. Although accurate determination of concentrations of amino acids in interstitial fluid is extremely complex, with microdialysis, sequential changes in ECF content of amino acids can be readily estimated within defined brain regions. Synaptic accumulation of EAA could result from increased release (from neurotransmitter or metabolic pools) or suppression of neuronal and glial re-uptake. Calculated efflux rates provide estimates of regional ECF content of compounds of interest (e.g., for striatal glutamate $1-2 \mu \mathrm{m})$.

Using microdialysis, Hagberg et al. found that during acute global ischemia cortical and striatal extracellular fluid glutamate and aspartate concentrations rose markedly in fetal sheep (6). We developed a method for microdialysis in striatum and hippocampus of postnatal day 7 rats, and studied amino acid efflux in the perinatal rodent focal ischemia model. Striatal ECF amino acid efflux was stable over 3 to 4 hours of sampling, and neither exposure to $8 \%$ oxygen or carotid ligation alone altered efflux (54). During the evolution of hypoxic-ischemic injury, increases ( $>3$-fold) in striatal glutamate efflux were detected, but the patterns differed from findings in adult brain. Glutamate efflux peaks were transient, and their timing varied (54). In contrast, in an adult rodent middle cerebral artery occlusion stroke model, striatal ECF glutamate concentration increased to $>60$ times baseline 1 to 3 hours later (55). In hippocampus, using a slightly different experimental protocol, we found a progressive rise in glutamate efflux with increasing duration of hypoxia; the time of maximal efflux coincided with the threshold for ischemic injury and values returned to baseline inmediately post-hypoxia (56). To facilitate more detailed comparison of sequential changes in glutamate and glutamine efflux, for each animal, values were normalized, and expressed as a percentage base- 
line (averaged from first three fractions) (Figure 1). Mean glutamate efflux peaked early in the second hour of hypoxia while glutamine efflux declined progressively. In contrast with glutamate, glutamine efflux declined gradually; the diverging trends suggest that systemic derangements such as dehydration were unlikely to account for the increase in glutamate efflux observed. The significance of the glutamine decline is uncertain; inhibition of the glial enzyme glutamine synthetase, which converts glutamate to glutamine, could account for both a reduction in glutamine efflux and synaptic glutamate accumulation (57). Awareness of the role of endogenous glycine in potentiating activation of NMDA receptors (58) prompted interest in analysis of glycine release; although no significant change in hippocampal glycine efflux was detected, our data revealed a trend towards increased glycine efflux in the second hour of hypoxia (56). Other investigators, using somewhat different dialysis methods in the same animal model, found that in cerebral cortex, ECF concentrations of glutamate and glycine rose acutely in hypoxic-ischemic cortex, and that while glutamate concentrations retum to normal posthypoxia, glycine concentrations remain elevated (59).

In adult brain, aspartate efflux generally increases in parallel with changes in glutamate efflux during ischemia $(5,60)$; however, we found no consistent increase in hippocampal aspartate efflux. This difference likely reflects lower synaptic concentrations of aspartate in immature brain; whether this developmental difference in EAA metabolism has pathophysiologic significance as to mechanisms of neuronal injury is unknown.

It is important to acknowledge evidence suggesting that increased extracellular glutamate concentrations alone are not sufficient to produce brain injury $(61,62)$. In the adult brain, the balance between excitatory and inhibitory amino acid neurotransmitter concentrations may correlate better with injury than extracellular glutamate alone (62). Of interest, in contra-distinction with studies in adult brain, baseline hippocampal GABA efflux was often undetectable in immature rodents, and no increases were detected with hypoxia-ischemia. Immaturity of GABAergic innervation may also be a contributing factor to the pathophysiological differences in the evolution of ischemic neuronal injury between immature and adult brain. Factors such as intrinsic variation in cellular susceptibility to excitotoxic injury and regional activity of endogenous neuromodulatory compounds are also likely to play critical roles in determining the extent of ischemic neuronal damage.

Neuroprotection with EAA antagonists. The most convincing evidence that EAA contribute to the pathogenesis of perinatal hypoxic-ischemic brain injury comes from neuroprotection studies with EAA antagonists. Several investigators have demonstrated that the non-competitive NMDA antagonist MK-801 protects the immature rat brain from focal hypoxicischemic injury. McDonald et al. (7) found that in seven day old rats that underwent right carotid ligation and were treated with $1 \mathrm{mg} / \mathrm{kg}$ MK-801 immediately before or 75 minutes after the onset of hypoxia (three hours total duration, in $8 \%$ oxygen) the severity of brain injury was reduced, assessed by comparison of cerebral hemisphere weights five days later, as compared with untreated litter-mates. The same treatment also attenuated the acute ipsilateral loss of EAA receptor binding observed 24 hours post-hypoxia in hippocampus and striatum (63). MK-801 administered immediately before or one hour into hypoxia (two hours total duration, in $8 \%$ oxygen) also prevented post-hypoxic-ischemic impairment in a learning and memory task at 30-days age and prevented hippocampal CA1 and CA3 pyramidal neuronal loss as assessed at 60-days age (64).

Figure 2 compares the distribution of histopathology in two animals that underwent carotid ligation and hypoxic exposure on PND 7, one of which was treated with MK-801; in the untreated animal, sacrificed on PND 12, there is prominent unilateral forebrain injury, with marked substance loss in striatum hippocampus, and cortex. In this MK-801-treated animal there was considerable attenuation of injury; however, it is important to consider that there is considerable variability in the efficacy of MK-801 against hypoxic-ischemic injury in this model. In contrast, the same dose of $\mathrm{MK}-801$ ( $1 \mathrm{mg} / \mathrm{kg})$ consistently completely prevents pure NMDA-induced injury (65).

In a closely related injury model, in which low atmospheric pressure was combined with unilateral carotid ligation to elicit focal hypoxic-ischemic brain injury in the immature rat, treatment with MK-801 $1 \mathrm{mg} / \mathrm{kg}$, prior to hypobaric exposure, markedly decreased the severity of ipsilateral brain damage (66). In a model more closely approximating global perinatal cerebral hypoxia-ischemia (bilateral carotid ligation plus one hour in $8 \%$ oxygen), Hattori et al. (67) demonstrated attenuation of cortical and striatal damage by administration of MK-801 $10 \mathrm{mg} / \mathrm{kg}$ shortly after hypoxia, and complete prevention of damage in survivors if the same high dose was administered immediately before hypoxia (but with increased acute mortality).

In adult animals, it has been suggested that the beneficial effects of MK-801 were attributable to MK-801induced hypothermia (18). In the hypobaric-ischemia model, a mild elevation in body temperature was associated with MK-801 treatment (66); neither McDonald et al. (7) or Ford et al. (64) reported body or brain temperature measurements. However, when 
temperature was monitored in unlesioned seven day old rats after treatment with the same dose $(1 \mathrm{mg} / \mathrm{kg})$ of MK-801, only slight reductions were observed $\left(0.98 \pm 0.08^{\circ} \mathrm{C}, \mathrm{n}=4\right)(68)$, and in lesioned seven day old rats pretreated with $\mathrm{MK}-801,10 \mathrm{mg} / \mathrm{kg}$, rectal temperature over a 24 hour period did not differ from controls (69). Thus, in immature rodents, hypothermia cannot account for neuroprotection.

The efficacy of other EAA antagonists has also been tested in the same model. Treatment with kynurenate, which blocks both NMDA and non-NMDA receptors, prior to hypoxia, reduced cerebral edema (70); administration of the same dose of kynurenate after hypoxia-ischemia attenuated ipsilateral hemisphere weight loss, an accurate measure of the severity of brain injury (71). Similarly, treatment with dextromethorpan, another non-competitive NMDA antagonist, prior to hypoxia, reduced the incidence of frank ipsilateral cerebral infarction (72).

A recent study in a model of incomplete global cerebral ischemia in the piglet yielded different results; MK-801 provided incomplete neuroprotection, limited to the hippocampus (73). Differences in the pathophysiology of ischemic injury (e.g., global or focal), and drug metabolism could account for such discrepancies in neuroprotective efficacy in different experimental paradigms.

No published studies have examined the neuroprotective effficacy of AMPA antagonists such as NBQX in perinatal ischemic brain injury. Optimal protective regimens for cerebral ischemia may require blockade of both NMDA and non-NMDA receptors (74), and such combination therapies have not yet been evaluated.

\section{Conclusions}

Thus, in perinatal rodent brain there is strong evidence that EAA play a major role in the pathogenesis of focal ischemic injury. To what extent these observations are relevant to treatment of ischemic brain injury in human infants remains uncertain. In considering treatment with EAA antagonists, an important issue that must be acknowledged is their potential detrimental effects in the developing brain. Since EAA play critical roles in normal synaptic maturation, EAA blockade could disrupt normal developmental processes, and the adverse impact of EAA antagonists will require careful evaluation before such drugs come into use clinically. Drugs that blocked excessive EAA release, or enhanced re-uptake might provide neuroprotection more selectively than receptor antagonists. Another potentially important pharmacologic strategy that must be explored is the development of combination therapies, targeting multiple components of the complex biochemical cascade that leads to irreversible ischemic injury, including EAA receptor over-activation, concurrently.

\section{Acknowledgements}

The research project was supported by USPHS NS 26142 and a grant from the American Heart Association of Michigan (to FSS).

\section{References}

1. Choi DW. Rothman SM (1990) The role of glutamate neurotoxicity in hypoxic-ischemic neuronal death. Annu Rev Neurosci 13: 171-182

2. Jorgensen MB, Diemer NH (1982) Selective neuron loss after cerebral ischemia in the rat: Possible role of transmitter glutamate. Acta Neurol Scand 66: 536-46

3. Simon RP, Swan JH, Griffiths T, Meldrum BS (1984) Blockade of $\mathrm{N}$-methyl-D-aspartate receptors may protect against ischemic damage in the brain. Science 226: 850-852

4. Wieloch T, Lindvall O, Blomqvist $P$, Gage $F$ (1984) Evidence for amelioration of ischemic neuronal damage in the hippocampal formation by lesions of the perforant path. Neurol Res 7: 24-26

5. Benveniste H, Drejer J, Schousboe A, Diemer NH (1984) Elevation of the extracellular concentrations of glutamate and aspartate in rat hippocampus during transient cerebral ischemia monitored by intracerebral microdialysis. J Neurochem 43: 1369-1374

6. Hagberg $H$, Andersson P, Kjellmer I, Thiringer $K$, Thordstein $M$ (1987) Extracellular overflow of glutamate, aspartate, GABA, and taurine in cortex and basal ganglia of fetal lambs during hypoxia-ischemia. Neurosci Lett 768: 311-317

7. McDonald JW, Silverstein FS, Johnston MV (1987) MK-801 protects the neonatal brain from hypoxic-ischemic damage. Eur J Pharmacol 140: 359-361

8. Choi DW (1990) Methods for antagonizing glutamate neurotoxicity. Cerebrovasc Brain Metab Rev 2: 105-147

9. Choi DW (1990) Cerebral hypoxia: Some new approaches and unanswered questions. J Neurosci 10: 2493-2501

10. Watkins JC, Krogsgaard-Larsen P, Honore T (1990) Structure-activity relationships in the development of excitatory amino acid receptor agonists and competitive antagonists. Trends Pharmacol Sci 11: 25-33

11. Lodge D. Johnson KM (1990) Noncompetitive excitatory amino acid receptor antagonists. Trends Pharmacol Sci 11: 81-86

12. Young $A B$, Fagg GE (1990) Excitatory amino acid receptors in the brain: Membrane binding and receptor autoradiographic approaches. Trends Pharmacol Sci 11: 126-133

13. Reynolds IJ, Miller RJ (1990) Allosteric modulation of $\mathrm{N}$-methyl-D-aspartate receptors. Adv Pharmacol 21: 101126

14. Williams K, Hanna JL, Molinoff PB (1991) Developmenta changes in the sensitivity of the $\mathrm{N}$-methyl-D-aspartate receptor to polyamines. Mol Pharmacol 40: 774-782

15. Kochhar A, Zivin JA, Lyden P, Mazzarella V (1988) Glutamate antagonist therapy reduces neurologic deficits produced by focal central nervous system ischemia. Arch Neurol 45: 148-153

16. Park CK, Nehls DG, Graham DI, Teasdale GM, McCulloch J (1988) The glutamate antagonist MK-801 reduces focal ischemic brain damage in the rat. Ann Neurol 24: 543-551

17. Simon R, Shiraishi $K(1990) \mathrm{N}$-methyl-D-aspartate antagonist reduces stroke size and glucose metabolism. Ann Neurol 27: 606-611 
18. Buchan A Pulsinelli WA (1990) Hypothermia but not the $N$ methyl-D-aspartate antagonist, MK-801, attenuates neuronal damage in gerbils subjected to transient global ischemia. J Neurosci 10: 311-316

19. Lanier WL, Perkins WJ, Ruud B, Milde JH, Michenfelder JD (1990) The effect of dizocilipine maleate (MK-801), an antagonist of the $\mathrm{N}$-methyl-D-aspartate receptor, on neurological recovery and histopathology following complete cerebral ischemia in primates. J Cereb Blood Flow Metab 10: 252-261

20. Olney JW, Labruyere J, Price MT (1989) Pathological changes induced in cerebrocortical neurons by phencyclidine and related drugs. Science 244: 1360-1362

21. Olney JW, Labruyere J, Wang G, Wozniak DF, Price MT. Sesma MA (1991) NMDA antagonist neurotoxicity: Mechanism and prevention. Science 254: 1515-1518

22. Sheardown MJ, Nielsen EO, Hansen AJ, Jacobsen $P$ Honore T (1990) 2,3-Dihydroxy-6-nitro-7-sulfamoyl-benzo (F) quinoxaline: A neuroprotectant for cerebral ischemia. Science 247: $571-574$

23. Judge ME, Sheardown MJ, Jacobsen $P$, Honore $T$ (1991) Protection against postischemic behavioral pathology by the alpha-amino-3-hydroxy-5-methyl-4-isoxazolepropionic acid (AMPA) antagonist 2,3-dihydroxy-6-nitro-7-sulfamoylbenzo (f) quinoxaline (NBOX) in the gerbil. Neurosci Lett 133: $291-294$

24. Buchan AM, Li H. Cho S, Pulsinelli WA (1991) Blockade of the AMPA receptor prevents CA1 hippocampal injury following severe but transient forebrain ischemia in adult rats. Neurosci Lett 132: 255-258

25. Pellegrini-Giampietro DE, Bennett MV, Zukin RS (1991) Differential expression of three glutamate receptor genes in developing rat brain: An in situ hybridization study. Proc Nati Acad Sci USA 88: 4157-4161

26. Rothman SM, Olney JW (1986) Glutamate and the pathophysiology of hypoxic-ischemic brain damage. Ann Neurol 19: 105-111

27. Choi DW (1987) lonic dependence of glutamate neurotoxicity. J Neurosci 7:369-379

28. Uematsu D, Greenberg JH, Arali N, Reivich M (1991) Mechanism underlying protective effect of MK-801 against NMDA-induced neuronal injury in vivo. J Cereb Blood Flow Metab 11: 779-785

29. Novelli A, Reilly JA, Lysko PG, Henneberry RC (1988) Glutamate becomes neurotoxic via the $N$-methyl-D-aspartate receptor when intracellular energy levels are reduced. Brain Res 451: 205-212

30. Beal MF (1992) Does impairment of energy metabolism result in excitotoxic neuronal death in neurodegenerative diseases. Ann Neurot 31: 119-130

31. Lazarewicz JW, Wroblewski JT, Palmer ME, Costa E (1988) Activation of $\mathrm{N}$-methyl-D-aspartate-sensitive glutamate receptors stimulates arachidonic acid release in primary cultures of cerebellar granule cells. Neuropharmacology 27: 765-769

32. Yu AC, Chan PH, Fishman RA (1986) Effects of arachidonic acid on glutamate and gamma-aminobutyric acid uptaké in primary cultures of rat cerebral cortical astrocytes and neurons. J Neurochem 47: 1181-1189

33. Markwell MAK, Berger SP, Paul SM (1990) The polyamine synthesis inhibitor alpha-difluoromethylornithine blocks NMDA-induced neurotoxicity. Eur J Pharm 182: 607-609

34. Porcella A, Fage D, Voltz C, Carter C, Scatton B, Bartholini $G$ (1991) Difluoromethyl ornithine protects against the neurotoxic effects of intrastriatally administered $\mathrm{N}$-methylD-aspartate in vivo. Eur J Pharm 199: 267-269

35. Garthwaite J, Charles SL, Chess-Williams R (1988) Endothelium-derived relaxing factor release on activation of NMDA receptors suggests role as intercellular messenger in the brain. Nature 336: 385-388

36. Dawson VL, Dawson TM, London ED, Bredt DS, Snyder SH (1991) Nitric oxide mediates glutamate neurotoxicity in primary cortical cultures. Proc Natl Acad Sci USA 88: 63866371

37. Nowicki JP, Duval D, Poignet H Scatton B (1991) Nitric oxide mediates neuronal death after focal cerebra ischemia in the mouse. Eur J Pharmacol 204: 339-340

38. McDonald JW, Silverstein FS, Johnston MV (1988) Neurotoxicity of NMDA is markedly enhanced in developing rat central nervous system. Brain Res 459: 200-203

39. Ikonomidou C, Mosinger JL, Salles KS, Labruyere J, Olney JW (1989) Sensitivity of the developing rat brain to hypobaric/ischemic damage parallels sensitivity to $\mathrm{N}$-methylaspartate toxicity. J Neurosci 9: 2809-2818

40. Zaczek R, Coyle JT (1982) Excitatory amino acid analogues: Neurotoxicity and seizures. Neuropharmacology 21: 15-26

41. Silverstein FS, Chen R, Johnston MV (1986) The glutamate analogue quisqualic acid is neurotoxic in striatum and hippocampus of immature rat brain. Neurosci Lett 71: 13-18

42. Young RS, Petroff OA, Aquila WJ, Yates J (1991) Effects of glutamate, quisqualate and $\mathrm{N}$-methyl-D-aspartate in neonatal brain. Exp Neurol 111: 362-368

43. Tremblay $E$, Roisin MP, Represa A, Charriaut-Marlangue $C$ Ben-Ari $Y$ (1988) Transient increased density of NMDA binding sites in the developing rat hippocampus. Brain Res 461: 393-396

44. McDonald JW, Johnston MV, Young AB (1990) Differential ontogenic development of three receptors comprising the NMDA receptor/channel complex in the rat hippocampus. Exp Neurol 110: 237-247

45. Insel TR, Miller LP, Gelhard RE (1990) The ontogeny of excitatory amino acid receptors in rat forebrain I. N-methylD-aspartate and quisqualate receptors. Neuroscience 35: 31-43

46. Miller LP, Johnson AE, Gelhard RE, Insel TR (1990) The ontogeny of excitatory amino acid receptors in rat forebrain 11. Kainic acid receptors. Neuroscience 35: 45-51

47. Hamon B, Heinemann U (1988) Developmental changes in neuronal sensitivity to excitatory amino acids in area CA1 of the rat hippocampus. Brain Res 466: 286-290

48. Bowe MA, Nadler JV (1990) Developmental increase in the sensitivity to magnesium of NMDA receptors on CA1 hippocampal pyramidal cells. Dev Brain Res 56: 55-61

49. Kleckner NW, Dingledine $R$ (1991) Regulation of hippocampal NMDA receptors by magnesium and glycine during development. Brain Res 11: 151-159

50. Wasterlain CG, Hattori $H$, Yang C, Schwartz PH, Fujikawa DG, Morin AM, Dwyer BE (1990) Selective vulnerability of neuronal subpopulations during ontogeny reflects discrete molecular events associated with normal brain development. In: Neonatal Seizures, Wasterlain CG, Vert $P$ (eds.), pp. 69-81, Raven Press: New York

51. Rice JE, Vannucci RC, Brierley JB (1981) The influence of immaturity on hypoxic-ischemic brain damage in the rat. Ann Neurol 9: 131-141

52. Silverstein FS, Buchanan K, Johnston MV (1984) Pathogenesis of hypoxic-ischemic brain injury in a perinatal rodent model. Neurosci Lett 49: $271-277$ 
53. Silverstein FS, Buchanan K, Johnston MV (1986) Perinatal hypoxia ischemia disrupts striatal high affinity $3 \mathrm{H}$-glutamate uptake into synaptosomes. J Neurochem 47: 1614-1619

54. Gordon KE, Simpson J, Statman D, Silverstein FS (1991) Effects of perinatal stroke on striatal amino acid efflux in rats studied with in vivo microdialysis. Stroke 22: 928-932

55. Hillered L, Hallstrom A, Segersvard S, Persson L, Ungerstedt U (1989) Dynamics of extracellular metabolites in the striatum after middle cerebral artery occlusion in the rat monitored by intracerebral microdialysis. J Cereb Blood Flow Metab 9: 607-616

56. Silverstein FS, Naik B, Simpson J (1991) Hypoxia-ischemia stimulates hippocampal glutamate efflux in perinatal rat brain: An in vivo microdialysis study. Pediatr Res 30: 587590

57. Oliver CN, Starke-Reed PE, Stadtman ER, Liu GJ, Carney JM. Floyd RA (1990) Oxidative damage to brian proteins, loss of glutamine synthase activity and production of freeradicals during ischemia/reperfusion-induced injury to gerbil brain. Proc Natl Acad Sci USA 87: 5144-5147

58. Johnson JW, Ascher $P$ (1987) Glycine potentiates the NMDA response in cultured mouse brain neurons. Nature 325: 529-531

59. Andine P, Sandberg M, Bagenholm R, Lehmann A, Hagberg $H$ (1991) Intracellular and extracellular change of amino acids in the cerebral cortex of the neonatal rat during hypoxic-ischemia. Dev Brain Res 64: 115-120

60. Benveniste $H$, Jorgensen MB, Sandberg $M$, Christensen $T$, Hagberg H, Diemer NH. (1989) Ischemic damage in hippocampal CA1 is dependent on glutamate release and intact innervation from CA3. J Cereb Blood Flow Metab 9: 629-639

61. Globus MYT, Ginsberg MD, Dietrich WD, Busto R, Schienberg $P$ (1987) Substantia nigra lesion protects against ischemic damage in the striatum. Neurosci Lett 80: 251256

62. Globus MYT, Busto R, Martinez E, Valdes I, Dietrich WD, Ginsberg MD (1991) Comparative effect of transient global ischemia on extracellular levels of glutamate, glycine and gamma-aminobutyric acid in vulnerable and non-vulnerable brain regions in the rat. J Neurochem 57: 470-478

63. Silverstein FS, MCDonald JW, Bommarito M, Johnston MV (1990) Effects of hypoxia-ischemia and MK-801 treatment on the binding of a phencyclidine analogue in the developing rat brain. Stroke 21: 310-315

64. Ford LM, Sanberg PR, Norman AB, Fogelson MH (1989) MK-801 prevents hippocampal neurodegeneration in neonatal hypoxic-ischemic rats. Arch Neurol 46: 1090-1096

65. McDonald JW, Silverstein FS, Cardona D, Hudson C, Chen R, Johnston MV (1990) Systemic administration of MK-801 protects against $\mathrm{N}$-methyl-D-aspartate- and quisqualatemediated neurotoxicity in perinatal rats. Neuroscience 36 : $589-599$

66. Oney JW, Ikonomidou C, Mosinger JL, Frierdich G (1989) MK-801 prevents hypobaric-ischemic neuronal degeneration in infant rat brain. J Neurosci 9: 1701-1704

67. Hattori $H$, Morin AM, Schwartz PH, Fujikawa DG, Wasterlain CG (1989) Posthypoxic treatment with MK-801 reduces hypoxic-ischemic damage in the neonatal rat. Neurology 39: $713-718$

68. Chen CK, MCDonald JW, Trescher WH, Johnston MV (1990) MK-801 transiently decreases cerebral temperature in perinatal rats. Soc Neurosci Abstr 16: 195
69. Hattori H, Wasterlain CG (1991) Hypothermia does not explain MK-801 neuroprotection in a rat model of neonatal hypoxic-ischemic encephalopathy. Neurology 41: 330

70. Simon RP, Young RSK, Stout S, Cheng J (1986) Inhibition of excitatory neurotransmission with kynurenate reduces brain edema in neonatal anoxia. Neurosci Lett 71: 361-364

71. Andine $P$, Lehmann A, Eliren K, Wennberg E, Kjellmer $I_{\text {, }}$ Nielsen T, Hagberg $H$ (1988) The excitatory amino acid antagonist kynurenic acid administered after hypoxicischemia in neonatal rats offers neuroprotection. Neurosci Lett 90: 209-212

72. Prince DA, Feeser HR 1988 Dextromethorphan protects against cerebral infarction in a rat model of hypoxia-ischemia. Neurosci Lett 85: 291-296

73. LeBlanc $M H$, Vig V, Smith B, Parker CC, Evans OB, Smith EE (1991) MK-801 does not protect against hypoxic-ischemic brain injury to piglets. Stroke 22: 1270-1275

74. Mosinger JL, Price MT, Bai HY, Xiao H, Wozniak DF, Olney JW (1991) Blockade of both NMDA and non-NMDA receptors is required for optimal neuroprotection against ischemic neuronal degeneration in the in vivo adult mammalian retina. Exp Neurol 113: 10-17 